\title{
Fluxos de comércio internacional nos setores de insumos básicos de Brasil, Rússia, Índia e China (BRIC) no período 1996-2007
}

\author{
Clésio Lourenço Xavier* \\ Daniela Fernanda Yamane ${ }^{* *}$
}

RESUMO - Nas duas últimas décadas, abertura comercial e maiores taxas de crescimento econômico de países em desenvolvimento como Brasil, Rússia, Índia e China (BRIC) tem sido uma novidade no ambiente econômico internacional, pressionando a demanda internacional de commodities agrícolas e minerais. A partir desta constatação, o objetivo desse trabalho é analisar, os fluxos de comércio internacional nos setores de metais não-ferrosos selecionados (prata, cobre, chumbo, alumínio e níquel) das economias emergentes do BRIC no período de 1996 a 2007 com base nos indicadores de comércio internacional: market-share e vantagem comparativa revelada.

Palavras-chave: BRIC. Insumos-básicos. Fluxos de comércio internacional.

\section{INTRODUÇÃO}

Este artigo avalia o desempenho dos setores de metais não ferrosos selecionados dos países integrantes do BRIC no período recente, sendo que tal revisão procura explicar os atuais padrões de comércio internacional com destaque para o aumento das exportações oriundas de países em desenvolvimento (BRIC) nas duas últimas décadas.

De acordo com Servo (1997), a importância do setor de alumínio está na variedade de produtos derivados dele devido às propriedades de leveza, baixa densidade, baixo peso, alta condutibilidade elétrica e características químicas que permitem formação de ligas com vários outros minerais como, cobre, zinco, manganês, entre outros. Podem ser utilizados na construção civil, transporte, material elétrico, máquinas e equipamentos, embalagens, tendo elevado índice de reciclagem. Sua produção depende das reservas naturais de bauxita e de elevados investimentos em pesquisa e inovação, fatores esses responsáveis pela concentração da produção mundial, além disso, a energia elétrica é grande responsável por seus custos, por isso países que possuem preços elevados de energia elétrica sofrem obstáculos na produção. Apesar dessas dificuldades a importância de investimentos nesse setor está nas perspectivas

\footnotetext{
* Doutor em Economia pela Universidade Estadual de Campinas. É professor adjunto do Instituto de Economia - IE - Universidade Federal de Uberlândia. Endereço eletrônico: clesio@ie.ufu.br.

** É Iniciante Científica de Curso de Ciências Econômicas. Instituto de Economia - IE - Universidade Federal de Uberlândia. Endereço eletrônico: daniela_yamane@yahoo.com.br.
} 
de sua crescente demanda que, de acordo com pesquisas, duplicará até 2020, sendo o maior demandante a China.

Segundo Andrade (2000) o níquel é utilizado na sua maioria para a produção de aços inoxidáveis, pois tem propriedades como a grande resistência mecânica à corrosão e à oxidação. Tem demanda também na construção civil, bens de consumo e indústria automobilística. Os custos que incorre estão na mineração e fundição, além de custos de refino e depreciação, sendo também um obstáculo a oferta de crédito necessário devido às etapas de pesquisa requeridas para sua produção, esses fatores ocasionaram a concentração em três empresas: uma russa, outra brasileira e uma anglo-australiana.

Quanto ao cobre sua maior destinação é para as indústrias de material elétrico, devido à sua alta condutividade de eletricidade e calor, é também utilizado na produção de ligas especiais, tubos, laminados e construção civil. As maiores distribuições encontram-se no Chile, Estados Unidos, China e pequena parte no Brasil. Seus maiores custos envolvem o processamento contínuo como custos de mineração, moagem, refino do mineral, reservas limitadas na superfície terrestre e além desses existem também os obstáculos quanto ao elevado tempo e o custo de obtenção de licenças ambientais. Tudo isso acaba ocasionando a concentração da produção principalmente em empresas chilenas, anglo-australiana e norteamericana (ANDRADE, 1997).

\section{NOTA METODOLÓGICA}

Foram gerados dados secundários referentes às exportações e importações do BRIC de insumos básicos selecionados (prata, cobre, níquel, alumínio e chumbo) dos anos de 1996 a 2007. Como fonte foi utilizada a base de dados da UNCTAD que oferece dados anuais dos fluxos de comércio dos países em dólares e, a partir desses foram calculados alguns indicadores de comércio exterior como o market-share que se refere à parcela de mercado obtido pelo país, calculado em relação ao total exportado mundialmente. Também foi calculado o indicador Vantagens Comparativas Reveladas que incorpora a participação de um determinado país nas exportações mundiais totais, indicando se o país possui ou não vantagem comparativa nas exportações de determinado produto. Quando o país tem uma vantagem comparativa com determinado produto em relação à economia mundial tem-se VCR $>1$.

14 
3 DESEMPENHO COMERCIAL DOS BRICS NOS SETORES DE INSUMOS BÁSICOS

\subsection{PARTICIPAÇÃO DE MERCADO DO BRIC EM SETORES DE MINERAIS NÃO- FERROSOS SELECIONADOS NO PERÍODO DE 1996 - 2007}

A seguir são apresentados os indicadores de market-shares do BRIC para cada produto selecionado (prata, cobre, níquel, alumínio e chumbo), comparando a participação e o desenvolvimento desses setores em quatro triênios 1996-1998, 1999-2001, 2002-2004 e 2005-2007.

TABELA 1 - MARKET-SHARE NO SETOR DE PRATA: COMPARAÇÃO ENTRE OS PAÍSES DO BRIC - $1996-2007$

\begin{tabular}{l|c|c|c|c}
\hline País/Ano & $\mathbf{1}^{\circ}$ trie & $\mathbf{2}^{\circ}$ trie & $\mathbf{3}^{\circ}$ trie & $\mathbf{4}^{\circ}$ trie \\
\hline Brasil & $0,14 \%$ & $0,24 \%$ & $0,61 \%$ & $0,30 \%$ \\
Índia & $0,02 \%$ & $0,00 \%$ & $0,04 \%$ & $0,09 \%$ \\
China & $0,17 \%$ & $2,35 \%$ & $10,68 \%$ & $15,56 \%$ \\
\hline FONTE: & Elaboração & própria, a & partir & de \\
UNCTAD (2009). & &
\end{tabular}

TABELA 2 - MARKET-SHARE NO SETOR DE COBRE: COMPARAÇÃO ENTRE OS PAÍSES DO BRIC - 1996 -2007

\begin{tabular}{lcc|c|c|c}
\hline País/Ano & $\mathbf{1}^{\circ}$ trie & $\mathbf{2}^{\circ}$ trie & $\mathbf{3}^{\circ}$ trie & $\mathbf{4}^{\circ}$ trie \\
\hline Brasil & $0,45 \%$ & $0,41 \%$ & $0,54 \%$ & $0,79 \%$ \\
Rússia & $3,80 \%$ & $3,75 \%$ & $3,68 \%$ & $4,10 \%$ \\
Índia & $0,07 \%$ & $0,27 \%$ & $1,31 \%$ & $2,32 \%$ \\
China & $1,57 \%$ & $1,99 \%$ & $2,87 \%$ & $4,41 \%$ \\
\hline FONTE: & Elaboração própria, a partir & de \\
UNCTAD (2009).
\end{tabular}

Conforme pode ser visto na Tabela 1, dentre os países constituintes do BRIC, a maior participação no mercado de prata no total de exportações do BRIC no quarto triênio e o maior crescimento são representados pela China que teve participação de 0,17\% no triênio de 1996-1998 e cresceu de forma exponencial durante os anos seguintes, atingindo 15,56\% no último período analisado 2005-2007, o que representa um crescimento de aproximadamente 9053\% no período. Brasil e Índia apesar de apresentarem crescimento no decorrer dos anos, correspondem a pequena porcentagem do market-share, sendo que nos últimos anos analisados possuem uma participação de $0,3 \%$ e $0,09 \%$ respectivamente.

Observando os dados da Tabela 2 dentre os países constituintes do BRIC constatase que todos eles tiveram em geral um desenvolvimento positivo em suas exportações de cobre de 1996 a 2007. Dentre eles os que mais se destacaram foram China, com 4,41\% no triênio 2005-2007, depois Rússia com participação de 4,1\%, que apesar de dois triênios de pequena queda (1999 a 2004) retomou o crescimento no período subsequente; em terceiro lugar vem Índia com 2,32\%, sendo dentre os metais não ferrosos selecionados deste país o que obtêm maior participação, perdendo apenas para o zinco; por último, o Brasil com $0,79 \%$. 
TABELA 3 - MARKET-SHARE NO SETOR DE NÍQUEL: COMPARAÇÃO ENTRE OS PAÍSES DO BRIC - 1996 - 2007

\begin{tabular}{lrrrrr}
\hline País/Ano & $\mathbf{1}^{\circ}$ trie & $\mathbf{2}^{\circ}$ trie & $\mathbf{3}^{\circ}$ trie & $\mathbf{4}^{\circ}$ trie \\
\hline Brasil & $0,81 \%$ & $1,25 \%$ & $1,26 \%$ & $1,21 \%$ \\
Rússia & $24,58 \%$ & $21,66 \%$ & $27,41 \%$ & $27,34 \%$ \\
Índia & $0,03 \%$ & $0,04 \%$ & $0,05 \%$ & $0,11 \%$ \\
China & $0,82 \%$ & $1,03 \%$ & $1,17 \%$ & $1,95 \%$ \\
\hline FONTE: & Elaboração & própria, a & partir & de \\
UNCTAD (2009).
\end{tabular}

TABELA 4 - MARKET-SHARE NO SETOR DE ALUMÍNIO: COMPARAÇÃO ENTRE OS PAÍSES DO BRIC - $1996-2007$

\begin{tabular}{lcc|c|c|c}
\hline País/Ano & $\mathbf{1}^{\circ}$ trie & $\mathbf{2}^{\circ}$ trie & $\mathbf{3}^{\circ}$ trie & $\mathbf{4}^{\circ}$ trie \\
\hline Brasil & $2,97 \%$ & $2,74 \%$ & $2,65 \%$ & $2,61 \%$ \\
Rússia & $10,11 \%$ & $9,66 \%$ & $7,30 \%$ & $7,40 \%$ \\
Índia & $0,39 \%$ & $0,56 \%$ & $0,61 \%$ & $0,64 \%$ \\
China & $1,26 \%$ & $1,48 \%$ & $4,58 \%$ & $6,41 \%$ \\
\hline FONTE: & Elaboração & própria, a & partir & de \\
UNCTAD (2009). & &
\end{tabular}

Com a Tabela 3, dentre os países constituintes do BRIC contata-se um market-share elevado da Rússia no que se refere ao níquel, correspondente a 27,34\% no quarto triênio, sendo dentre os metais não ferrosos selecionados é o que apresenta maior participação neste país. Aliás, a Rússia vem apresentando desde 1996-1998 um market-share elevado nas exportações de níquel correspondente a 24,58\%. Os outros países apresentam uma participação inferior, sendo que no último período o Brasil apresentou uma pequena queda, após três períodos seguidos de crescimento, terminando sua participação com 1,21\%. Índia e China apresentaram um pequeno crescimento constante no transcorrer dos quatro triênios.

De acordo com a Tabela 4, dentre os países constituintes do BRIC observa-se uma ligeira queda no market-share das exportações de alumínio no período de 1996 a 2007 do Brasil, com uma diminuição de 2,97\% no primeiro período para 2,61\% no último período. No entanto apesar dessa pequena queda, esse é o metal não ferroso selecionado que o Brasil tem maior participação no mercado. A Rússia decresceu de 10,11\% para 7,40\% sua participação internacional no mercado de alumínio. Por outro lado, Índia e China aumentaram sua participação: a Rússia passou de $0,39 \%$ para $0,64 \%$ e a China de $1,26 \%$ para $6,41 \%$, representando um crescimento dos de ambos os países, embora em escalas absolutas muito distintas.

A análise da Tabela 5 demonstra que a exportação de chumbo nos países do BRIC, apenas a participação da China é significativa, tendo um market-share de 15,82\% no último período analisado, sendo o produto deste país dentre os metais não ferrosos selecionados de maior participação. Todos os outros países do BRIC apresentaram um aumento no decorrer dos anos, tendo, no entanto pequena participação na exportação deste metal não-ferroso. 
TABELA 5 - MARKET-SHARE NO SETOR DE CHUMBO: COMPARAÇÃO ENTRE OS PAÍSES DO BRIC - $1996-2007$

\begin{tabular}{l|r|r|r|r}
\hline País/Ano & $\mathbf{1}^{\circ}$ trie & $\mathbf{2}^{\circ}$ trie & $\mathbf{3}^{\circ}$ trie & $\mathbf{4}^{\circ}$ trie \\
\hline Brasil & $0,01 \%$ & $0,01 \%$ & $0,01 \%$ & $0,03 \%$ \\
Rússia & $0,25 \%$ & $0,20 \%$ & $0,32 \%$ & $1,50 \%$ \\
Índia & $0,10 \%$ & $0,04 \%$ & $0,19 \%$ & $0,66 \%$ \\
China & $9,91 \%$ & $16,80 \%$ & $17,30 \%$ & $15,82 \%$ \\
\hline FONTE: Elaboração própria, a partir de UNCTAD \\
(2009).
\end{tabular}

TABELA 6 - SOMA DO MARKET-SHARE DO BRIC NOS SETORES SELECIONADOS: EVOLUÇÃO NOS ANOS DE 1996 - 2007

\begin{tabular}{l|r|r|r|l}
\hline País/Prod & $\mathbf{1}^{\circ}$ trie & $2^{\circ}$ trie & $\mathbf{3}^{\circ}$ trie & $4^{\circ}$ trie \\
\hline Prata & $0,32 \%$ & $2,59 \%$ & $11,33 \%$ & $15,95 \%$ \\
Cobre & $5,89 \%$ & $6,42 \%$ & $8,39 \%$ & $11,62 \%$ \\
Níquel & $26,24 \%$ & $23,97 \%$ & $29,87 \%$ & $30,60 \%$ \\
Alumínio & $14,73 \%$ & $14,45 \%$ & $15,13 \%$ & $17,07 \%$ \\
Chumbo & $10,27 \%$ & $17,04 \%$ & $17,82 \%$ & $18,00 \%$ \\
\hline
\end{tabular}

FONTE: Elaboração própria, a partir de UNCTAD (2009).

A Tabela 6 apresenta uma síntese da evolução do total da participação no mercado internacional do BRIC nos setores de metais não-ferrosos selecionados (prata, cobre, níquel, alumínio e chumbo). Observando do primeiro período de 1996-1998 ao último de 2005-2007 deve ser registrado um crescimento do setor de prata de $48884 \%$, tendo no período inicial um market-share de $0,32 \%$ e nos anos mais recentes uma participação de $15,95 \%$. O de cobre cresceu $97,2 \%$, tendo passado de 5,89\% para $11,62 \%$ e no setor de níquel também se contatou um crescimento de $16,6 \%$, tendo no início um market-share de 26,34\% e de 2005 a 2007 uma participação de 30,6\%. O setor de alumínio também ampliou sua participação em 15,8\%, tendo a princípio um market-share de 14,73\% e nos últimos anos avaliados uma participação de 17,07\%. Por fim, o setor de chumbo cresceu 75,2\%, tendo um market-share de 10,27\% no primeiro triênio e de 18\% no quarto triênio. De forma geral, China e Rússia lideram o mercado internacional de metais não ferrosos no período recente.

\subsection{VANTAGEM COMPARATIVA REVELADA DO BRIC EM SETORES DE MINERAIS NÃO-FERROSOS SELECIONADOS NO PERÍODO DE 1996-2007.}

A seguir são apresentados os indicadores de Vantagens Comparativas Reveladas (VCRs) do BRIC para cada produto selecionado (prata, cobre, níquel, alumínio, chumbo) indicando se o país possui ou não vantagem relativa de custos a partir da eficiência de suas especializações comerciais, supondo que as diferentes dotações de fatores resultam em uma estrutura padronizada de exportações de determinado produto nos quatro triênios de 19961998, 1999-2001, 2002-2004 e 2005-2007. 
TABELA 7 - VANTAGEM COMPARATIVA REVELADA NO SETOR DE PRATA: COMPARAÇÃO ENTRE OS PAÍSES DO BRIC: $1996-2007$

\begin{tabular}{lccccc|c}
\hline País/Ano & $\mathbf{1}^{\circ}$ trie & $\mathbf{2}^{\circ}$ trie & $\mathbf{3}^{\circ}$ trie & $\mathbf{4}^{\circ}$ trie \\
\hline Brasil & 0,14 & 0,25 & 0,60 & 0,25 \\
Índia & 0,01 & 0,00 & 0,02 & 0,04 \\
China & 0,05 & 0,55 & 1,75 & 1,86 \\
\hline FONTE: & Elaboração & própria, & a & partir & de \\
UNCTAD (2009). & & & & &
\end{tabular}

TABELA 8 - VANTAGEM COMPARATIVA REVELADA NO SETOR DE COBRE: COMPARAÇÃO ENTRE OS PAÍSES DO BRIC: $1996-2007$

\begin{tabular}{lrrrrrr}
\hline País $/$ Ano & $\mathbf{1}^{\circ}$ trie & $\mathbf{2}^{\circ}$ trie & $\mathbf{3}^{\circ}$ trie & $\mathbf{4}^{\circ}$ trie \\
\hline Brasil & 0,46 & 0,45 & 0,37 & 0,66 \\
Rússia & 2,37 & 2,41 & 1,95 & 1,60 \\
Índia & 0,01 & 0,01 & 0,00 & 0,01 \\
China & 0,47 & 0,49 & 0,47 & 0,53 \\
\hline FONTE: & Elaboração & própria, & a & partir & de \\
UNCTAD (2009). & & & & &
\end{tabular}

De acordo com a Tabela 7, em relação ao setor de prata, entre os quatro países do BRIC durante todo o período analisado, apesar de apresentarem uma tendência crescente do VCR, constata-se que o único país que possui um VCR maior que a unidade é a China, apresentando o valor de 1,86 no último triênio, o que representa sua vantagem comparativa do setor de prata em relação a economia mundial, enquanto os outros estão em desvantagem comparativa.

A Tabela 8 mostra o VCR no setor de cobre, constatando que, entre todos os países envolvidos, no período de 1996 a 2007 o único país que possui vantagem comparativa é a Rússia, com valores acima de 1 durante todo o período, embora tenha apresentado um decréscimo de 2,37 em 1998-1998 para 1,6 em 2005-2007. Brasil, Índia e China apresentam desvantagem comparativa, apesar de estarem apresentando uma evolução positiva do VCR durante todo o período analisado.

Na Tabela 9 acima são apresentados os valores do VCR no setor de níquel. Nela são apresentados resultados significativos para o BRIC, sendo que o maior destaque foi obtido pela Rússia com VCR de 15,48 em 1996-1998 e de 10,66 em 2005-2007. Índia apresentou crescimento de sua vantagem de 1,76 em 1996-1998 para 4,46 em 2005-2007 e o Brasil oscilou com crescimento no início e decréscimo no final do período terminando com valor praticamente neutro de seu VCR.

De acordo com a Tabela 10, o VCR do BRIC no setor de alumínio é maior que 1 para Rússia e Brasil, sendo que Rússia apresentou um decréscimo de 6,38 no primeiro triênio para 2,89 no último triênio e o Brasil no mesmo sentido reduziu seu VCR de 3,02 para 2,18. Índia e China apresentaram desvantagens comparativas no setor de alumínio, com valores menores que 1. 
TABELA 9 - VANTAGEM COMPARATIVA REVELADA NO SETOR DE NÍQUEL: COMPARAÇÃO ENTRE OS PAÍSES DO BRIC: $1996-2007$

\begin{tabular}{lrrrrrr}
\hline País/Ano & $\mathbf{1}^{\circ}$ trie & $\mathbf{2}^{\circ}$ trie & $\mathbf{3}^{\circ}$ trie & $\mathbf{4}^{\circ}$ trie \\
\hline Brasil & 0,82 & 1,36 & 1,22 & 1,01 \\
Rússia & 15,48 & 13,98 & 14,69 & 10,66 \\
Índia & 1,76 & 0,22 & 4,17 & 4,46 \\
China & 0,23 & 0,26 & 0,19 & 0,23 \\
\hline FONTE: & Elaboração & própria, & a & partir & de \\
UNCTAD (2009). & & &
\end{tabular}

TABELA 10 - VANTAGEM COMPARATIVA REVELADA NO SETOR DE ALUMÍNIO: COMPARAÇÃO ENTRE OS PAÍSES DO BRIC: $1996-2007$

\begin{tabular}{lcccccc}
\hline País/Ano & $\mathbf{1}^{\circ}$ trie & $\mathbf{2}^{\circ}$ trie & $\mathbf{3}^{\circ}$ trie & $\mathbf{4}^{\circ}$ trie \\
\hline Brasil & 3,02 & 2,98 & 2,58 & 2,18 \\
Rússia & 6,38 & 6,20 & 3,91 & 2,89 \\
Índia & 0,24 & 0,36 & 0,32 & 0,25 \\
China & 0,37 & 0,36 & 0,75 & 0,76 \\
\hline FONTE: & Elaboração & própria, & a & partir & de \\
UNCTAD (2009). & & & &
\end{tabular}

TABELA 11 - VANTAGEM COMPARATIVA REVELADA NO SETOR DE CHUMBO: COMPARAÇÃO ENTRE OS PAÍSES DO BRIC: 1996 - 2007

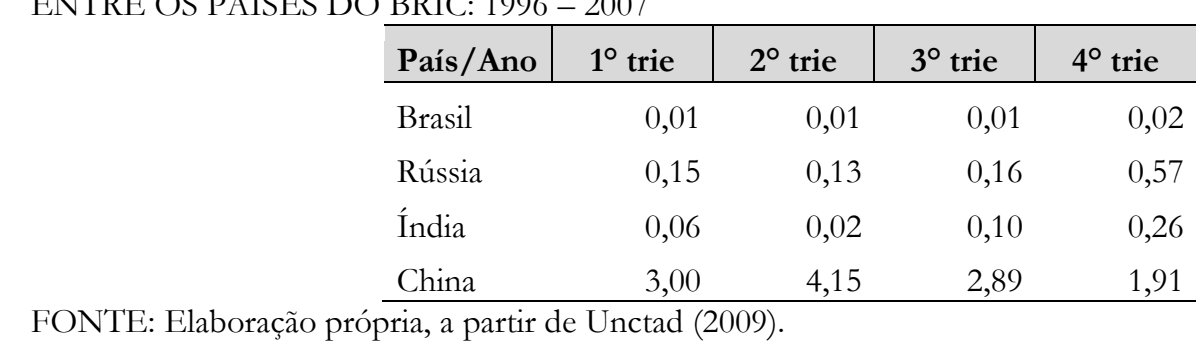

A análise da Tabela 11 do VCR no setor de chumbo demonstra que o único país dentre todos os pesquisados que apresentou um indicador de VCR maior que 1 foi a China apesar da diminuição do índice de 3 em 1996-1998 para 1,91 em 2005-2007. Os outros componentes do BRIC apesar de apresentarem uma tendência de crescimento de suas vantagens comparativas reveladas, ainda encontram-se em desvantagem comparativa.

\section{CONCLUSÃO}

A análise dos indicadores de desempenho exportador dos BRIC no setor de minerais não ferrosos revelou uma evolução positiva de tais países no período recente, não obstante a forte assimetria presente intrabloco: a China apresenta forte taxa de crescimento nas exportações de todos os setores de minerais não ferrosos ao longo do período, embora a Rússia ainda exerça a liderança nessa participação no último triênio nos setores de alumínio e níquel. O Brasil possui uma participação mais significativa apenas em alumínio, embora bem inferior á participação da Rússia. 


\section{REFERÊNCIAS}

ANDRADE, M. L. A. Níquel - Novos Parâmetros de Desenvolvimento. Área de Operações Industriais 2 - AO2. Maio, 2000.

ANDRADE, M. L. A. Indústria do Cobre. Área de Operações Industriais - AO2. Agosto 1997.

SERVO, L. M. S. A indústria Brasileira do Alumínio. In: GARCIA, F., FARINA, E.M.M.Q. \& Alves, M. C. Padrão de Concorrência e Competitividade da Indústria de Materiais de Construção. São Paulo, Editora Singular.

UNCTAD. Disponível em: <www.unctad.org>. 